\title{
Effect of grass-clover forage and whole-wheat feeding on the sensory quality of eggs
}

\author{
Klaus Horsted, ${ }^{a *}$ Marianne Hammersh $ø j^{b}$ and Bodil H Allesen-Holm ${ }^{c}$
}

\begin{abstract}
BACKGROUND: A sensory panel evaluated the sensory profile of eggs from hens from three experimental systems: (1) an indoor system $\times$ normal layer diet (InL), (2) a grass-clover forage system $\times$ normal layer diet (GrL), and (3) a grass-clover forage system $x$ whole wheat and oyster shells (GrW).

RESULTS: The taste of the albumen was significantly more 'watery' and the yolks a darker yellow/orange in the eggs from the GrL and GrW groups. The yolk was darkest from the GrW group. The yolks from the InL and GrW groups had a significantly more 'fresh', less 'animal', 'cardboard', and 'intense' aroma than the GrL group. The taste of the yolks from the InL and GrW groups was significantly more 'fresh' and less 'cardboard'-like compared to the GrL group. The yolks tasted significantly less 'sulfurous' in the GrW group than in the GrL group.
\end{abstract}

CONCLUSION: The combination of a high feed intake from a grass-clover pasture and the type of feed allocated is an important factor in relation to the sensory quality of eggs. Thus, a less favourable sensory profile of eggs was found from hens on a grass-clover pasture and fed a normal layer diet.

(c) 2009 Society of Chemical Industry

Keywords: albumen; free-range; grass-clover; sensory profile; wheat; yolk

\section{INTRODUCTION}

Organic agriculture is undergoing tremendous growth at present due to increased consumer demand for foods that focus on animal welfare and protection of the environment during production, as well as on product safety and quality. ${ }^{1}$ For organic egg production in Denmark, the market share has risen to approximately $16 \%$ of the total egg production, which makes organic eggs one of most successful organically produced animal products. ${ }^{2}$ However, very little has been published on egg sensory quality in organic production systems, which shows that very little is known about the sensory quality of eggs from these systems. Thus, the popularity of organically produced eggs is mainly due to an ethical quality dimension or that consumers believe these eggs are healthier or taste better.

One of the main differences between organic and traditional egg production systems is that organically reared hens must have access to an outdoor area with vegetation. ${ }^{3}$ However, this is primarily required for animal welfare reasons, since organic-egg producers usually do not include feed intake from the outdoor area in their feeding management programmes, just as cultivation of the outdoor area in order to supply the poultry with nutrients is rarely seen. A traditional feeding strategy also involves importing a concentrate feed mixture that fulfils the hens' requirement and feeding this in the henhouse. This has the consequence that most hens prefer to stay in the henhouse or in the area closest to it. ${ }^{4,5}$ However, recent studies indicate that, to a large extent, the potential contribution of nutrients to the diet from an outdoor area has been overlooked and underestimated. ${ }^{6,7}$ These studies suggest that laying hens actually are able to cover much of their nutrient requirements from the outdoor area if abundant attractive vegetation is available. Moreover, it was demonstrated that if the hens were nutrient-restricted by feeding whole wheat and oyster shells as the only supplementary feed, they had a higher intake of plant material and other feed items such as insects and earthworms from the outdoor area. Such a forage-based feeding strategy increases the use of locally produced feed items in accordance with the principles of organic agriculture. ${ }^{8}$ However, the production of eggs in a forage- and grain-based system may not be applicable in the usual organic production system with relatively large flocks of laying hens. On the other hand, such a low-input system may be of particular interest for premiumprice niche production strategies with high added value in rural districts. Thus, the eggs produced can be considered as speciality products because of the fulfilment of several quality dimensions such as environmental friendliness, high animal welfare and use of locally produced feeds. Moreover, eggs from a forage-based system may be healthier for humans. Thus, Lopez-Bote et al. ${ }^{9}$ found that eggs from hens in free-range systems with access to

\footnotetext{
* Correspondence to: Klaus Horsted, Aarhus University, Department of Agroecology and Environment, P.O. Box 50, DK-8830 Tjele, Denmark. E-mail: Klaus.Horsted@agrsci.dk

a Aarhus University, Department of Agroecology and Environment, P.O. Box 50, DK-8830 Tjele, Denmark

b Aarhus University, Department of Food Science, P.O. Box 50, DK-8830 Tjele, Denmark

c University of Copenhagen, Department of Food Science-Sensory Science, Rolighedsvej 30, 5th floor, DK-1958 Frederiksberg C, Denmark
} 
grass had a higher concentration of total omega- 3 fatty acids and $\alpha$-tocopherol without adverse oxidative effects.

Since, for decades, the majority of egg-laying systems have been intensive ones, only very limited interest has been shown in the effect of feeding forage material ${ }^{10}$ and of outdoor foraging on the sensory quality of eggs. There also seems to be a paucity of historical studies ${ }^{11}$ and reviews ${ }^{12}$ on this subject in the literature. It is our hypothesis that intake of forage material by hens, and the combination of forage and the type of allocated feed influence the sensory profile of eggs. Thus, the objective of this study was to test for distinct differences in the sensory profile of eggs from hens in a forage-based system with a grass-clover pasture and fed whole wheat or a traditional layer diet in comparison with eggs from hens kept in an indoor system and fed a traditional layer diet.

\section{EXPERIMENTAL}

The breed selected for the experiment was a cross between White Leghorn and New Hampshire supplied by the breeding company 'Hellevad' in Denmark. Prior to the experimental period all hens had been reared in an extensive forage-based system with abundant access to vegetation (ryegrass Lolium perenne, red clover Trifolium pratense and white clover Trifolium repens). From 20 weeks of age and to the introduction to the experiment at 27 weeks of age, the hens were reared in two groups and fed either a commercially prepared layer diet or whole wheat and oyster shells to ensure they had become habituated to the feed used in the experiment.

\section{Grouping of experimental hens}

In the experimental period (27-31 weeks of age), a total of 120 laying hens were divided into three groups according to housing system and feed type. The hens in the GrL (Grass-clover/Layer diet) and GrW (Grass-clover/Wheat) groups continued in an organic free-range system, and the hens in the InL (Indoor/Layer diet) group were randomly selected from the two rearing groups and placed in a house with $1 \mathrm{~m}^{2}$ per hen and with no outdoor access. The GrL and InL groups were fed a commercially prepared layer diet and hens in the GrW group were fed whole wheat and oyster shells as the only supplementary feed (Table 1). In the GrL and GrW groups the feed and water were allocated in the outdoor area under a rain shield to motivate the hens to go outside. The outdoor areas consisted of $2 \times 3$ plots with grass-clover, which meant that hens were moved to a new plot twice, i.e. every 10 days during the experimental period to ensure sufficient access to vegetation for all hens during the experimental period and to prevent the vegetation from being worn down. In each plot the hens had $10 \mathrm{~m}^{2}$ per hen, i.e. a total of $30 \mathrm{~m}^{2}$ per hen for the whole period. The experiment took place in the autumn, when there was only a limited growth of the vegetation. The percentage of cover of ryegrass, white clover, red clover and bare ground is given in Table 2 for each of the plots after the hens had been allocated to the plots. The proportion of the ground surface covered by each plant species and bare ground was visually estimated using a $0.25 \mathrm{~m}^{2}$ metal frame that was randomly placed at four different locations in each plot. The proportions in Table 2 are based on the rearing period and the experimental period as well.

For the sensory evaluation, the eggs were collected 30 days after the hens had been introduced to the experiment to exclude any influence from preceding rearing conditions on egg sensory quality. It was ensured that eggs for sensory assessment were laid no longer than $24 \mathrm{~h}$ before collection.
Table 1. Dietary composition and analysed nutrient content of the layer diet and the wheat

\begin{tabular}{|c|c|c|}
\hline & Layer diet & Wheat \\
\hline \multicolumn{3}{|l|}{ Ingredient (g kg $\left.{ }^{-1}\right)$} \\
\hline Wheat, organic & 440 & 1000 \\
\hline Soya cake toasted, organic & 134 & - \\
\hline Maize, organic & 100 & - \\
\hline Oat, organic & 70 & - \\
\hline Calcium carbonate & 68 & - \\
\hline Sunflower cake, organic & 60 & - \\
\hline Soya bean toasted, organic & 47.2 & - \\
\hline Greenmeal, organic & 28 & - \\
\hline Oyster shells & 20 & - \\
\hline Maize gluten $60 \%$ & 14 & - \\
\hline Mono calcium phosphate & 12.1 & - \\
\hline Rock salt & 2.5 & - \\
\hline Vitamin premix & 2.5 & - \\
\hline Sodium bicarbonate & 0.7 & - \\
\hline Betain anhydrate & 0.7 & - \\
\hline Bergazyme & 0.3 & - \\
\hline \multicolumn{3}{|l|}{ Nutrient content (g kg $\left.{ }^{-1}\right)$} \\
\hline Crude protein & 181 & 85 \\
\hline Crude fat & 47 & 13 \\
\hline Starch & 345 & 588 \\
\hline Sugar & 27 & 23 \\
\hline Lysine & 81 & 26 \\
\hline Methionine & 29 & 14 \\
\hline Cystine & 33 & 21 \\
\hline Threonine & 69 & 27 \\
\hline ME (MJ kg-1) & 10.5 & 11.9 \\
\hline
\end{tabular}

\section{Sensory assessment}

The sensory assessment took place at the Sensory Laboratory at the University of Copenhagen, Department of Food Science, and consisted of a pilot study, two training sessions and the final assessment. The pilot study was carried out 2 weeks prior to the sensory assessment to develop a preliminary set of attributes to be used at the training sessions, and to produce recipes for reference materials. For example, the reference material for the attribute 'cardboard' was hardboiled yolk/albumen from fresh commercial eggs stored near wet cardboard. The references were used to enable the panel to become familiar with the sensory attributes and to unify their perception of the specific attributes. In the pilot study no differences were found in relation to texture of the albumen and yolk, and the aroma of the albumen. Thus, attributes relating to the taste of the albumen, the aroma and taste and colour of the yolk were chosen as the most important attributes to describe the differences in the sensory profile. Five eggs from each treatment were used in the pilot study.

The training sessions and the assessment were carried out on three successive days. The eggs were collected on four successive days, and the eggs collected on the last two days were used for the assessment. The eggs were stored at $4{ }^{\circ} \mathrm{C}$ for 8 or 9 days prior to the assessment.

\section{Cooking and serving of egg samples}

Three hours before the training sessions as well as the assessment, the eggs were boiled for 10-10.5 min depending on individual 
Table 2. Proportion (\%) of cover of ryegrass, red clover, white clover and bare ground observed in plots with hens fed a layer diet or whole wheat

\begin{tabular}{|c|c|c|c|c|c|c|}
\hline & \multicolumn{2}{|c|}{ Plot 1 ( $1-10$ days $)$} & \multicolumn{2}{|c|}{ Plot 2 ( $11-20$ days $)$} & \multicolumn{2}{|c|}{ Plot 3 ( $21-30$ days) } \\
\hline & $\begin{array}{l}\text { Layer } \\
\text { diet }\end{array}$ & Wheat & $\begin{array}{c}\text { Layer } \\
\text { diet }\end{array}$ & Wheat & $\begin{array}{c}\text { Layer } \\
\text { diet }\end{array}$ & Wheat \\
\hline Rye grass & $6.0(6.2)$ & $5.0(3.6)$ & $1.5(1.0)$ & $2.8(2.1)$ & $1.3(1.3)$ & $9.8(9.2)$ \\
\hline Red clover & $74.3(13.5)$ & $66.0(9.3)$ & $68.8(7.7)$ & $41.0(11.6)$ & $74.7(17.2)$ & $55.0(14.2)$ \\
\hline White clover & $18.7(11.1)$ & $22.5(5.0)$ & $26.3(4.8)$ & $27.5(14.4)$ & $18.7(10.3)$ & $21.2(4.8)$ \\
\hline Bare ground & $1.0(2.0)$ & $6.5(4.0)$ & $3.4(3.2)$ & $28.7(9.5)$ & $5.3(6.6)$ & $14.0(9.0)$ \\
\hline
\end{tabular}

egg weights, which ranged from 56 to $64 \mathrm{~g}$. The eggs were subsequently cooled with water for $15 \mathrm{~min}$, peeled and divided into albumen and yolk, both chopped separately. The chopped albumen from six eggs was pooled for each treatment and served in 10 portions (one for each assessor) and likewise the yolk. For the assessment four replications were used, i.e. 24 eggs were used for each treatment. The portions were served in individual plastic cups provided with close-fitting lids, and the albumen and yolk from the same replication were served simultaneously (one sample).

\section{Sensory profiling of eggs}

The sensory profiling of the egg samples was performed by a sensory panel, which consisted of ten assessors selected according to ISO $3972: 1991 .^{13}$ The assessment took place in a sensory evaluation laboratory fitted to meet the demands in ISO 8589 : 1988 and ASTM. ${ }^{14,15}$ A panel leader guided the training sessions and only the panel leader knew the identity of the samples during the training sessions as well as the final assessment.

On the first day of training the assessors were presented with six samples in three pairs. The attributes from the pilot study were discussed by the assessors after each sample pair, and some were changed to give a more precise description. On the second day of training the assessors were presented initially with four sample pairs, and subsequently the assessors were placed in separate booths with no contact with each other and served four more samples. The attributes were again discussed and a few were changed. All changes during the training sessions were decided by open panel discussions only by the assessors without any influence from the panel leader. After the second training session, the vocabulary for the assessment was finalised (Table 3). At the assessment on the third day, the assessors were placed in the booths and each served egg samples in a randomised order within each replication, all samples labelled with three-digit codes. The eggs were served at $20^{\circ} \mathrm{C} .{ }^{16,17}$ Each attribute was evaluated on a $15 \mathrm{~cm}$ unstructured line scale, with 15 as the highest score and 0 as the lowest. The anchor points were 'none' on the left side and 'extreme' on the right for all attributes. ${ }^{16,18,19}$ The two attributes of 'liking', which gives a subjective preference score of the involved assessors, were not included in the training sessions, but were added to the vocabulary afterwards. This was done to ensure that the assessors were not biased by the training in respect to liking the albumen and the yolk. The hedonic categories (liking of the albumen and the yolk) were set by the authors of this article and the panel leader. The FIZZ Network version 2.20 was used for electronic data collection. ${ }^{20}$

Table 3. The final reference schedule used for the sensory assessment Definitions of sensory attributes derived during vocabulary

Attribute and order of assessment development

Taste, albumen

1. Fresh (positive)

2. Sulfurous (negative)

3. Watery (neutral)

4. Feed (negative)

5. Cardboard (negative)

6. 'Liking' of the albumen

Aroma, yolk

7. Fresh (positive)

8. Sulfurous (negative)

9. Feed (negative)

10. Animal (negative)

11. Cardboard (negative)

12. Intensity (neutral)

\section{Colour of the yolk}

13. Yellow (neutral)

\section{Taste, yolk}

14. Fresh (positive)

15. Sweet (positive)

16. Sourish (positive)

17. Sulfurous (negative)

18. Feed (negative)

19. Cardboard (negative)

20. 'Liking' of the yolk
How strong is the taste of fresh albumen?

How strong is the taste of sulfur in the albumen?

How watery does the albumen taste?

How strong is the taste of feed (layer diet) in the albumen?

How strong is the taste of cardboard in the albumen?

Anchor points are 'do not like at all' and 'like very much'

How strong is the aroma of fresh yolk?

How strong is the aroma of sulfur in the yolk?

How strong is the aroma of feed (layer diet) in the yolk?

How strong is the aroma of animal in the yolk?

How strong is the aroma of cardboard in the yolk?

How intensive is the aroma of the yolk

From very light yellow to very dark yellow/reddish

How strong is the taste of fresh yolk?

How sweet does the yolk taste?

How sourish does the yolk taste?

How strong is the taste of sulfur in the yolk?

How strong is the taste of feed in the yolk?

How strong is the taste of cardboard in the yolk?

Anchor points are 'do not like at all' and 'like very much' 


\section{Statistical methods}

Analysis of variance was performed using the MIXED procedure in SAS. ${ }^{21}$ Four replications were used and each replication consisted of six eggs. 'Assessor' was used as random effect. The program PanelCheck version 1.2.1 was used to detect outliers in the raw data. ${ }^{22}$ In addition, a calculation of PCA (principal component analysis) models using the multivariate data analysis function in the program FIZZ Calculation was used as a guideline to outlier removal. ${ }^{20}$ It was found that four assessors had difficulties with one or two different attributes. In these cases data have been considered as outliers and were replaced by the average for the rest of the panel. ${ }^{23}$

\section{RESULTS}

The taste of the albumen significantly differed for the 'watery' attribute since the albumen was considered more watery from hens in the forage-based systems, independent of the type of supplementary feed (Table 4). No significant differences were found in relation to the other attributes for albumen taste and no significant differences were found for the 'liking' of the albumen.

On the yolk colour scale, the yolks from hens in the InL group scored 2.8 (SEM 0.41), which was significantly $(P<0.001)$ less yellow than the yolks from GrL group (score 10.4, SEM 0.41) and the GrW group (score 11.6, SEM 0.41). Moreover, the yolks from the GrW group were a significantly $(P<0.01)$ darker yellow/orange than the yolks from the GrL group.

The aroma of the yolk differed significantly for four out of six attributes. Thus, the eggs from hens in the GrW and the InL groups had yolks with more 'fresh', less 'animal' and 'cardboard' aroma and with a lower 'intensity' compared with the GrL group (Table 5).

The yolks from hens in the GrW and the InL groups tasted significantly more 'fresh' and less of 'cardboard' than yolks from hens in the GrL group (Table 6). The yolks from the hens in the GrW group had significantly less 'sulfurous' taste compared with the GrL group, and it also tended ( $P=0.061$ ) to be less compared with the yolks from the InL group (Table 6). Scores for 'liking' of the yolk were $8.5,4.9$ and 8.3 for the $\mathrm{InL}, \mathrm{GrL}$ and GrW groups, respectively $(P<0.001$, SEM 0.75), i.e. the assessors liked the yolks from the GrL group less than the yolks from the InL and GrW groups. No significant difference was found between the $\mathrm{InL}$ and GrW groups.

\section{DISCUSSION}

The objective of the present study was to test for distinct differences in the sensory profile of eggs from hens in three different production systems: an indoor system with hens fed a

Table 4. Scores and significance on taste attributes of the egg albumen, least square means and standard error of mean (SEM)

\begin{tabular}{|c|c|c|c|c|c|}
\hline & Fresh & $\begin{array}{c}\text { Sul- } \\
\text { furous }\end{array}$ & Watery & Feed & $\begin{array}{l}\text { Card- } \\
\text { board }\end{array}$ \\
\hline Grass-clover/Layer diet (GrL) & 6.5 & 6.5 & $7.8^{\mathrm{a}}$ & 3.7 & 4.1 \\
\hline Grass-clover/Wheat (GrW) & 7.5 & 5.9 & $8.0^{\mathrm{a}}$ & 2.9 & 3.4 \\
\hline Indoor/Layer diet (InL) & 7.8 & 6.8 & $6.1^{\mathrm{b}}$ & 2.6 & 3.7 \\
\hline SEM & 0.68 & 0.75 & 0.58 & 0.60 & 0.61 \\
\hline Significance $(P)$ & NS & NS & $<0.05$ & NS & NS \\
\hline
\end{tabular}

a,b Scores in a column not sharing a common superscript are significantly different $(P<0.05)$. traditional layer diet (InL), a forage-based system with hens having access to grass-clover pasture and fed either a traditional layer diet (GrL) or whole wheat and oyster shells (GrW).

The assessors evaluated the yolks from the hens in the foragebased systems as much darker than those with no outdoor access. Moreover, the yolks from the hens in the GrW group were perceived as significantly darker than those from the GrL group, which corresponds very well with a recent study, where the yolk colour was analysed objectively by a Minolta Chroma Meter (Minolta, Co., Ltd, Osaka, Japan). ${ }^{24}$ The darker yolk colour is attributed to the intake of plant material from the outdoor area, due to grass-clover having a high content of xanthophylls of up to $700 \mu \mathrm{g} \mathrm{g}^{-1}$ dry matter, depending on species and maturity stage, ${ }^{25,26}$ which affects the coloration of the egg yolk. ${ }^{27,28}$ Egg yolk colour is an important quality attribute for consumers, even though the preferred yolk colour has been found to vary between geographical areas. Studies on consumer preference indicate that the preferred colours range from moderate yellow to orange, i.e. from 8 to 14 on the Roche colour fan (scale 1-15), with most consumers preferring the darker yellow/orange yolk colours. ${ }^{28,29}$ The preference for the darker-coloured yolks is most likely related to consumers' perception that coloured foods have a better aroma and taste; ${ }^{30}$ in a historical study McCammon et al. ${ }^{31}$ found that darker-coloured yolks tended to score higher for taste. However, the present study indicates a more complex situation since taste and aroma of the yolk revealed a distinctly different profile between feed types for the hens kept in the forage-based system (groups GrL and GrW), despite the fact that the yolk colour scores for both groups were at the darker end of the scale (higher than 10). In general, the assessors rated the aroma and taste of the yolks from the GrW group more favourably than the yolks from the GrL group. In contrast, the assessors gave identical scores for aroma and taste attributes for the yolks from the $\mathrm{InL}$ and GrW groups despite the very different yolk colours. There was only a tendency for the yolks from the GrW group to have a slightly less sulfurous taste. The very similar assessment for the InL and GrW group is reflected in the 'liking of the yolk', since similar liking scores were given for the yolks from both groups. This shows that the sensory panel was able to distinguish the yolk colour effect from the taste and aroma of the yolk. There is no documentation in the literature that xanthophylls in egg yolk contribute directly to the aroma or taste of eggs; hence, consumer perception of darker yolks having a better sensory quality may be because xanthophyll sources, such as plants and algae, also contain aroma components that may affect the taste and aroma of the egg. In addition, xanthophylls like lutein, zeaxanthin and canthaxanthin have antioxidant activity, which may reduce lipid peroxidation and off-flavour development. ${ }^{32,33}$

The very distinct difference in the sensory profile of the yolks from the hens in the GrL and the GrW group may be due to the hens in the GrL group having a feed intake with a surplus of some nutrients. Even though laying hens are known to have an excellent ability to balance their feed intake to meet their nutritional requirements, ${ }^{34,35}$ hens in the GrL group could not select between different feeds because of the pelleted layer diet. As indicated by the yolk colour scores and previous studies, ${ }^{6,7}$ the hens in the GrL group had a considerable feed intake from the open-air run despite access to a well-balanced layer diet. However, the energy requirement could only be covered through the layer diet, just as layer-type hens typically attempt to consume the quantity of food necessary to meet their energy requirements. ${ }^{36}$ A higher intake of some nutrients may therefore occur due 
Table 5. Scores and significance on aroma attributes of the egg yolk, least square means and standard error of mean (SEM)

\begin{tabular}{lcccccc|} 
& Fresh & Sulfurous & Feed & Animal & Cardboard & Intensity \\
\hline Grass-clover/Layer diet (GrL) & $5.8^{\mathrm{a}}$ & 2.9 & 3.9 & $5.2^{\mathrm{a}}$ & $4.5^{\mathrm{a}}$ & $7.3^{\mathrm{a}}$ \\
Grass-clover/Wheat (GrW) & $7.4^{\mathrm{b}}$ & 2.3 & 3.0 & $3.2^{\mathrm{b}}$ & $3.1^{\mathrm{b}}$ & $5.8^{\mathrm{b}}$ \\
Indoor/Layer diet (InL) & $7.8^{\mathrm{b}}$ & 2.6 & 2.8 & $2.6^{\mathrm{b}}$ & $2.6^{\mathrm{b}}$ & $5.6^{\mathrm{b}}$ \\
SEM & 0.67 & 0.67 & 0.66 & 0.61 & 0.76 & 0.67 \\
Significance (P) & $=0.01$ & NS & NS & $<0.001$ & $<0.05$ & $<0.05$ \\
\hline a,b Scores in a column not sharing a common superscript are significantly different $(P<0.05)$. & & & \\
\hline
\end{tabular}

to the difference in nutrient composition of the feed items from the outdoor area (grass, clover, earthworms and insects), including a higher protein/energy ratio than the layer diet. This may lead to an excess of some amino acids such as lysine and methionine. ${ }^{6,24}$ We have found no studies on the effect of amino acids on the sensory quality of egg yolks. However, a study on the impact of dietary supplemental methionine sources on sensory measurements of odour-related compounds in broiler excreta demonstrated that supplemental methionine significantly influenced odour production in broiler excreta. ${ }^{37,38}$ Since the production of odorous volatiles is attributed to microbial activity of non-absorbable byproducts in the intestinal tract, it may be hypothesised that some of these volatile compounds (e.g. sulfur compounds) may be found in the yolk. Thus, in the present study, a surplus of the sulfur-containing amino acids methionine and cysteine might cause a stronger sulfur taste in the yolks from the GrL group compared to the GrW group, which presumably lacked sulfurous amino acids, because of the low content of sulfurous amino acids in the wheat.

In the study by Hammershøj and Steenfeldt, ${ }^{10}$ hens fed carrots and whole-plant corn silage as supplement to two experimental layer diets ( $0 \%$ vs $25 \%$ lupin) had a significantly higher score for the sulfur-like taste in yolks compared to hens receiving no roughage supplement. The authors suggested that this might be due to the roughage favouring the Gram-positive flora in the caecum and colon and thus the formation of malodorous compounds, presumably affecting the taste of the yolk negatively. However, the present study indicates that the type of feed allocated is important if hens have a high intake of plant material. Thus, the hens in the GrW group presumably had a higher intake of plant material, but simultaneously a significantly lower score for the sulfurous taste of the yolk than the GrL group.

The type of vegetation eaten by the hens may influence the sensory profile of the yolk, especially. Chickens are known to select between different plant species, ${ }^{39}$ just as the selection can depend on the type of feed allocated. A recent study suggested that laying hens fed a pelleted layer diet prefer clover, and hens fed whole wheat prefer grass, even though hens from both groups consumed clover as well as grasses. ${ }^{40}$ In the present study, there appeared to be more red clover in the plots with the GrL group. However, this does not indicate a lower intake of this plant species, since a higher foraging activity was found in the GrW group, which resulted in more wear on the vegetation as indicated by a higher percentage of bare ground (Table 2). It is plausible, however, that the hens in the present study selected red clover, white clover and rye grass differently in relation to feed type, but we have found no studies on the effect of these plant species on the sensory quality of eggs. However, a recent study on the meat quality of cull dairy cows fed red clover or grass silage showed a significantly higher concentration of polyunsaturated fatty acids, a lower concentration of vitamin $\mathrm{E}$, increased lipid oxidation and a higher sensory score for the attribute 'fishy' for the red clover silage treatment compared with the grass silage treatment. ${ }^{41}$ These parameters are all associated with a poorer quality and a higher risk of oxidative changes including off-flavours, which arguably is what happened in the present GrL treatment if the hens preferred eating clover at the expense of ryegrass. This would explain the generally higher scores for negative sensory attributes of GrL egg yolks compared with GrW egg yolks.

In conclusion, the eggs from hens on a grass-clover pasture fed a traditional layer diet had less favourable scores in several sensory quality attributes compared to eggs from hens in an indoor system fed the same feed type or to hens on a grass-clover pasture fed whole wheat and oyster shells. In contrast, the eggs from the hens in the two last-named groups mainly differed in yolk colour. Thus the type of feed allocated is an important consideration when hens are kept in a system where they may have a high intake of plant material. The effect of different plant species combined with different feeding strategies is still an area where there is scope for more research, just as studies on consumer perception of alternatively produced eggs are needed, and generally a thorough understanding of how different factors affect the sensory properties of eggs.

\begin{tabular}{|c|c|c|c|c|c|c|}
\hline & Fresh & Sweet & Sourish & Sulfurous & Feed & Cardboard \\
\hline Grass-clover/Layer diet (GrL) & $4.9^{\mathrm{a}}$ & 6.1 & 6.4 & $4.0^{\mathrm{a}}$ & 4.1 & $6.6^{\mathrm{a}}$ \\
\hline Grass-clover/Wheat (GrW) & $8.5^{\mathrm{b}}$ & 7.3 & 5.9 & $2.5^{\mathrm{b}}$ & 3.8 & $4.3^{b}$ \\
\hline Indoor/Layer diet (InL) & $7.7^{b}$ & 6.4 & 5.8 & $3.5^{\mathrm{ab}}$ & 3.1 & $3.5^{\mathrm{b}}$ \\
\hline SEM & 0.63 & 0.59 & 0.99 & 0.67 & 0.65 & 0.68 \\
\hline Significance $(P)$ & $<0.001$ & NS & NS & $<0.05$ & NS & $<0.001$ \\
\hline
\end{tabular}

a,b Scores in a column not sharing a common superscript are significantly different $(P<0.05)$. 


\section{REFERENCES}

1 Yiridoe EK, Bonti-Ankomah S and Martin RC, Comparison of consumer perceptions and preference toward organic versus conventional produced foods: A review and update of the literature. Renewable Agric Food Syst 20:193-205 (2005).

2 The Danish Plant Directorate, Vejledning om økologisk jordbrugsproduktion. Ministry of Food, Agriculture and Fisheries, Kgs. Lyngby, Denmark, p. 101 (2008).

3 Council of the European Union, Council Regulation (EC) No. 1804/1999 of 19 July 1999, supplementing Regulation (EEC) No. 2092/91 on organic production of agricultural products and indications referring thereto on agricultural products and foodstuffs to include livestock production. Off J Eur Commun L 222:1 - 28 (1999).

4 Bubier NE and Bradshaw $\mathrm{RH}$, Movement of flocks of laying hens in and out of the hen house in four free range systems. Br Poult SCi 39:S5-S6 (1998).

5 Hegelund L, Sørensen JT, Kjær JB and Kristensen IS, Use of range area in organic egg production systems: effect of climatic factors, flock size, age and artificial cover. Br Poult Sci 46:1 -8 (2005).

6 Horsted $\mathrm{K}$ and Hermansen JE, Whole wheat versus mixed layer diet as supplementary feed to layers foraging a sequence of different forage crops. Animal 1:575-585 (2007).

7 Horsted K, Hermansen JE and Ranvig H, Crop content in nutrientrestricted versus non-restricted organic laying hens with access to different forage vegetations. Br Poult Sci 48:177-184 (2007).

8 IFOAM, The IFOAM norms for organic production and processing, version 2005. IFOAM, Bonn, Germany (2005).

9 Lopez-Bote CJ, Sans Arias R, Rey Al, Castaño A, Isabel B and Thos J, Effect of free-range feeding on $n-3$ fatty acid and $\alpha$-tocopherol content and oxidative stability of eggs. Anim Feed Sci Technol 72:33-40 (1998).

10 Hammershøj M and Steenfeldt S, Effects of blue lupin (Lupinus angustifolius) in organic layer diets and supplementation with foraging material on egg production and some egg quality parameters. Poult Sci 84:723-733 (2005).

11 Heuser GF, Feeding Poultry, 2nd edition. John Wiley \& Sons, New York (1955).

12 Woese K, Lange D, Boess C and Bögl KW, A comparison of organically and conventionally grown foods - Results of a review of the relevant literature. J Sci Food Agric 74:281 - 293 (1997).

13 ISO 3972:1991, Sensory Analysis-Methodology-Method of Investigating Sensitivity of Taste. Ref. no. ISO 3972:1991 (E). International Organization for Standardization, Geneva, p. 7 (1991).

14 ISO 8589: 1988, Sensory analysis - General Guidance for the Design of Test Rooms. Ref. no. ISO 8589:1988 (E). International Organization for Standardization, Geneva, p. 9 (1988).

15 American Society for Testing and Materials, Physical Requirements. Guidelines for Sensory Evaluation Laboratories, STP 913. ASTM, Pennsylvania (1986).

16 ISO 13299:2003, Sensory Analysis - General Guidance for Establishing a Sensory Profile. Ref. No. ISO 13299:2003 (E). International Organization for Standardization, Geneva, p. 24 (2003).

17 American Society for Testing and Materials, Standard Guide for Serving Protocol for Sensory Evaluation of Foods and Beverages, E1871-06. ASTM, Pennsylvania (2006).

18 ISO 8586-1 : 1993, Sensory Analysis - General Guidance for the Selection, Training and Monitoring of Assessors. Ref. no. ISO 8586-1:1993 (E). International Organization for Standardization, Geneva, p. 15 (1993).

19 Meilgaard M, Civille GV and Carr BT, Measuring responses, in Sensory Evaluation Techniques, 4th edition. CRC Press, Boca Raton, pp. 43-57 (2007).

20 Biosystèmes. FIZZ Software Solution for sensory Analysis and Consumer Tests, [Online]. Available: http://www.biosystemes. com/data-collection,fizz-network.php [12 June 2009].
21 Littell RC, Milliken GA, Stroup WW and Wolfinger RD, SAS System for Mixed Models. SAS Institute, Cary, NC (1996).

22 Matforsk AS, The PanelCheck Project. [Online]. Available: http://www.panelcheck.com/ [24 June 2009].

23 Hoo KA, Tvarlapati KJ, Piovoso MJ and Hajare R, A method of robust multivariate outlier replacement. Comput Chem Eng 26:17-39 (2002).

24 Horsted K, Hammershøj M and Hermansen JE, Short-term effects on productivity and egg quality in nutrient-restricted versus nonrestricted organic layers with access to different forage crops. Acta Agric Scand Sect A 56:42-54 (2006).

25 Prache S, Priolo A and Grolier P, Persistence of carotenoid pigments in the blood of concentrate-finished grazing sheep: Its significance for the traceability of grass-feeding. J Anim Sci 81:360-367 (2003).

26 Cardinault N, Doreau M, Poncet C and Noziére P, Digestion and absorption of carotenoids in sheep given fresh red clover. Anim Sci 82:49-55 (2006).

27 Belyavin CC and Marangos AG, Natural products for egg yolk pigmentation, in Recent Advances in Animal Nutrition, ed. by Haresign W and Cole DJA. Butterworths, London, pp. 47-68 (1987).

28 Nys Y, Dietary carotenoids and egg yolk coloration - a review. Arch Geflügelkd 64:45-54 (2000).

29 Beardsworth PM and Hernandez J-M, Yolk colour - an important egg quality attribute. Int Poult Prod 12:17-18 (2004).

30 Christensen $\mathrm{CM}$, Effects of color on aroma, flavour and texture judgments of foods. J Food Sci 48:787-790 (1983).

31 McCammon RB, Pittman MS and Wilhelm LA, The odor and flavor of eggs. Poult Sci 13:95-101 (1934).

32 Ribaya-Mercado JD and Blumberg JB, Lutein and zeaxanthin and their potential roles in disease prevention. J Am Coll Nutr 23:567S-587S (2004).

33 Surai AP, Surai PF, Steinberg W, Wakeman WG, Speake BK and Sparks NHC, Effect of canthaxanthin content of the maternal diet on the antioxidant system of the developing chick. Br Poult Sci 44:612-619 (2003).

34 Rose SP and Kyriazakis I, Diet selection of pigs and poultry. Proc Nutr Soc 50:87-98 (1991).

35 Henuk YL and Dingle JG, Practical and economic advantages of choice feeding systems for laying poultry. World Poult Sci J 58:199-208 (2002).

36 Larbier M and Leclercq B, Nutrition and Feeding of Poultry. Nottingham University Press, Nottingham, p. 305 (1994).

37 Chavez C, Coufal CD, Niemeyer PL, Carey JB, Lacey RE, Miller RK, et al, Impact of dietary supplemental methionine sources on sensory measurement of odor-related compounds in broiler excreta. Poult Sci 83:1655-1662 (2004).

38 Chavez C, Coufal CD, Carey JB, Lacey RE, Beier RC and Zahn JA, The impact of supplemental dietary methionine sources on volatile compound concentrations in broiler excreta. Poult Sci 83:901-910 (2004).

39 Wood GM, Smith RT and Henderson DC, A crop analysis technique for studying the food habits and preferences of chickens on range. Poult Sci 42:304-309 (1963).

40 Horsted K, Hermansen JE and Hansen $\mathrm{H}$, Botanical composition of herbage intake of free-range laying hens determined by microhistological analysis of faeces. Arch Geflügelkd 71:145-151 (2007).

41 Lee MRF, Evans PR, Nute GR, Richardson RI and Scollan ND, A comparison between red clover silage and grass silage feeding on fatty acid composition, meat stability and sensory quality of the M. Longissimus muscle of dairy cull cows. Meat Sci 81:738-744 (2009). 